pÿA means-corrected estimate for the Arctic sea-ice volume in 19902019

\title{
Uotila, Petteri
}

2021-03-04

Uotila , P , Siponen , J , Rinne , E \& Tietsche , S 2021 , ' A means-corrected estimate for the pÿArctic sea-ice volume in 19902019 ' , vEGU21 , 19/04/2021 - 30/04/2021 . https://doi.org/10.5194/egusphere-egu

http://hdl.handle.net/10138/328515

https://doi.org/10.5194/egusphere-egu21-3840

cc_by_nc_nd

publishedVersion

Downloaded from Helda, University of Helsinki institutional repository.

This is an electronic reprint of the original article.

This reprint may differ from the original in pagination and typographic detail.

Please cite the original version. 
EGU21-3840, updated on 30 Mar 2021

https://doi.org/10.5194/egusphere-egu21-3840

EGU General Assembly 2021

(c) Author(s) 2021. This work is distributed under

the Creative Commons Attribution 4.0 License.

\title{
A means-corrected estimate for the Arctic sea-ice volume in 1990-2019
}

\author{
Petteri Uotila ${ }^{1}$, Joula Siponen ${ }^{1,2}$, Eero Rinne ${ }^{2}$, and Steffen Tietsche ${ }^{3}$ \\ ${ }^{1}$ University of Helsinki, Institute for atmospheric and earth system research, Helsinki, Finland (petteri.uotila@helsinki.fi) \\ ${ }^{2}$ Finnish Meteorological Institute \\ ${ }^{3}$ European Centre for Medium-Range Weather Forecasts
}

Decadal changes in sea-ice thickness are one of the most visible signs of climate variability and change. To gain a comprehensive understanding of mechanisms involved, long time series, preferably with good uncertainty estimates, are needed. Importantly, the development of accurate predictions of sea ice in the Arctic requires good observational products. To assist this, a new seaice thickness product by ESA Climate Change Initiative $(\mathrm{CCI})$ is compared to a set of five ocean reanalysis (ECCO-V4r4, GLORYS12V1, ORAS5 and PIOMAS).

The CCI product is based on two satellite altimetry missions, CryoSat-2 and ENVISAT, which are combined to the longest continuous satellite altimetry time series of Arctic-wide sea-ice thickness, 2002-2017. The CCI product performs well in the validation of the reanalyses: overall root-meansquare difference (RMSD) between monthly sea-ice thickness from $\mathrm{CCl}$ and the reanalyses ranges from 0.4-1.2 $\mathrm{m}$. The differences are a sum of reanalysis biases, such as incorrect physics or forcing, as well as uncertainties in satellite altimetry, such as the snow climatology used in the thickness retrieval.

The $\mathrm{CCl}$ and reanalysis basin-scale sea-ice volumes have a good match in terms of year-to-year variability and long-term trends but rather different monthly mean climatologies. These findings provide a rationale to construct a multi-decadal sea-ice volume time series for the Arctic Ocean and its sub-basins from 1990-2019 by adjusting the ocean reanalyses ensemble toward CCI observations. Such a time series, including its uncertainty estimate, provides new insights to the evolution of the Arctic sea-ice volume during the past 30 years. 